\title{
DEVELOPMENT OF ENERGY CHARACTERISTICS OF ELECTRIC DRIVES OF TECHNOLOGICAL EQUIPMENT AND NORMALIZATION OF ELECTRIC CONSUMPTION OF FAT-AND- OIL ENTERPRISE
}

\author{
Rashid Jalilov $^{1 *}$, Saidmurod Latipov², Alisher Choriyev ${ }^{3}$ \\ ${ }^{1}$ Bukhara engineering technological institute, associate professor of the department of Power Eninineering, DSc, Uzbekistan, \\ Bukhara region, 200100, Bukhara, street Murtazaev, 15 \\ ${ }^{2}$ Bukhara engineering technological institute, PhD student department of Power Eninineering, Uzbekistan, Bukhara region, 200100 , \\ Bukhara, street Murtazaev, 15 \\ ${ }^{3}$ Bukhara engineering technological institute, PhD student department of Power Eninineering, Uzbekistan, Bukhara region, 200100, \\ Bukhara, street Murtazaev, 15
}

\begin{abstract}
The article covers the development of energy characteristics of electric drives of technological equipment and normalization of electric consumption of fat-and-oil enterprise. The results of experimental research of energy characteristics of the consumed power $\mathrm{P}$ and specific electricity consumption $\mathrm{d}$ depending on hourly productivity $\mathrm{A}$ on the widely used oil-extracting units of MPSH types at "EVROSNAR" LLC enterprise are given. Nomenclature that fully covers the production processes and corresponds to the currently accepted indicators of accounting and control under the conditions of infactory economic accounting and a nomogram for determining the specific consumption of electricity per ton of seeds and oils in general for manufacturing is proposed.
\end{abstract}

\section{Introduction}

One of the feasible ways to solve the problem of increasing the reliability and accuracy of forecasts of energy and energy-economic indicators in power supply systems of industrial enterprises is their forecasting, taking into account the relationship with other indicators characterizing the production process. When implementing this method, the basics of probability theory and mathematical statistics are used.

At the operational stage, the problem under consideration is closely related to the problems of normalization the specific consumption of electricity (SCE) in industry. These problems, although much attention is paid to them in the literature, cannot be considered as solved. In the process of normalization of the SCE, it is advisable to distinguish two stages: the study of the SCE as random variables and their normalization. Representation of SCE as random variables puts forward special requirements for the sequence of their formation by production levels. The task of developing scientifically grounded standards of energy consumption should be solved in a complex with the tasks of organizing control and metering of electricity consumption $[1,2]$.

Among the numerous methods for assessing, analyzing and controlling power consumption modes, as well as standardizing SCE in industry, the most effective is the construction of energy characteristics (EC) of units, shops and the enterprise in general, expressing the dependence of the consumed power or SCE on number of factors, in particular, on volume of products (productivity), quality indicators of processed raw materials, etc. [2].

Construction of energy characteristics, expressing the dependence of energy consumption on product output over a calendar period should be considered as the most acceptable. This is also justified by the fact that the change in volume of manufactured products has the most significant effect on the energy efficiency and that these characteristics play an important role in the selection of the most energetically favorable operating modes of the equipment.

As an arguing value for constructing energy characteristics, which are the basis for analyzing and calculating electric power indicators at oil-extracting industry enterprises, it is advisable to take a unit of processed raw materials with subsequent conversion per unit of final product (oil). Electricity consumption is mainly related to the amount of processed seeds. The production of oil is not directly related to the consumption of electricity and depends on the oil content of the seeds and oil losses during the production process [2].

In the production of cottonseed oil, the most energyintensive units are the pre-extraction of oil - forepresses, which along with the braziers consume more than $20 \%$ of the total plant electricity consumption.

\section{Materials and Methods}

In this article, the results of our experimental studies of consumed power P and SCE d depending on the hourly productivity A on the widespread oil-extracting units of 
the MPSH types at the "EVROSNAR" LLC enterprise are given as an example. They have some design differences, different productivity and relatively high technical and economic indicators in comparison with other units of domestic and foreign production. The principle of operation of these presses is similar to the forepresses described in [2].

Proceeding from the fact that the recalculation of the productivity of the press to the indicator for seeds can be made using a simplified formula (1.2), the energy characteristics of the press are considered as a function of the produced oilcake, that is, $\mathrm{P}=\mathrm{f}(\mathrm{Ao})$ and $\mathrm{d}=\mathrm{f}(\mathrm{Ao})$ [2].

To obtain these characteristics, the Chebyshev method [3] is used, which allows determining the order of the correlation equation and its error.

We have experimentally measured the power consumption of the above types of forepress units, depending on their performance, which was regulated by opening the feeder leak.

The experiments were carried out as follows. The productivity of the press was measured by taking the oilcake shell into a special box (the sampling interval was $60 \mathrm{sec}$ ), weighed on centesimal scales and recalculated for 60 minutes (with the deduction of container). At the same time, the power was measured using an active energy meter, as well as ATK-2250 measuring claws.

The selection was carried out 3 times for each point. The amount of data was 12 for each type of aggregate with the same oilcake shell thickness.

In result of experimental measurements for productivity levels $0 ; 25 ; 50 ; 75$ and $100 \%$ and the implementation of the compiled algorithm, the equations of the energy characteristics of the power consumption and the specific electricity consumption for oil-extracting units of MPSH types were obtained: MPSH

$$
\begin{array}{r}
P_{a}=36.6+1.26 A_{\circ}+4.38 A_{\circ}^{2} \\
d_{a}=1.26+4.38 A_{\circ}+36.6 \frac{1}{A_{0}}
\end{array}
$$

Mathematical models of energy characteristics are obtained in $\mathrm{CI}+$ language according to algorithm shown in Fig. 1.

In Fig. 2, the energy characteristics of oil-extracting unit MPSH are constructed.

"EVROSNAR" LLC works continuously in around-theclock mode. Analysis of electricity consumption graphs for 2018-2019 shows uniform consumption of electricity by months of the year, except for the repair period of the enterprise (Table). In 2018, due to the irregular supply of cottonseeds for processing, monthly electricity consumption ranges from 240 thousand $\mathrm{kWh}$ to 310 thousand $\mathrm{kWh}$, i.e. the deviation is $77 \%$.
Table shows the consumption of electricity and gas by months of 2019.

Initial data for constructing energy characteristics of enterprise.

The main initial data for forecasting and determining the norms of electricity consumption are:

$>$ primary technical and technological documentation;

$>$ restored power supply schemes of the enterprise;

$>$ measurement results;

$>$ regulatory characteristics of electrical and technological equipment and raw materials, equipment passport data, standard indicators;

$>$ data on planned and actual specific electricity consumption for the past years;

$>$ working time fund (month, year);

$>$ plan of organizational-technical measures on electric energy saving, introduction of new equipment and technologies;

$>$ forecast data on the volume of products.

The total EC of departments, workshops and production facilities as a whole has been constructed, which limiting area of possible operating modes for the given type of equipment and level of operation. This allows determining the minimum levels of electricity consumption and SCE for various volumes of processed products. Depending on how much higher the actual level is from the minimum probable, it is possible to determine the reserves of energy efficiency.

Thereby, based on constructing the total extreme characteristics of workshops and production processes, the method for quantitatively assessing the reserves of energy efficiency associated with the irrational mode of the electric drive of technological equipment is proposed.

Based on the performed research, the authors proposed a new nomenclature and structure of SCE standards, covering all types of products - husks, oilcake, synthetic fatty acids (SFA), salad and packaged oils (Fig. 3).

Based on the performed research, a methodology for calculating and analyzing SCE norms for the production of refined cottonseed oil has been developed, which reflects the specifics of this production.

Along with the general factory standards, three infactory standards for production processes - forepress, extraction and on unrefined oil are recommended. These standards are based on the indicators of seed processing and reflect the level of electric drives (ED) of completed production processes.

The proposed nomenclature fully covers the production processes and corresponds to the currently accepted indicators of accounting and control under the conditions of in-factory cost accounting.

All analysis and all calculations according to the proposed methodology are carried out using power and SCE mathematical models depending on quantity of processed seeds. 


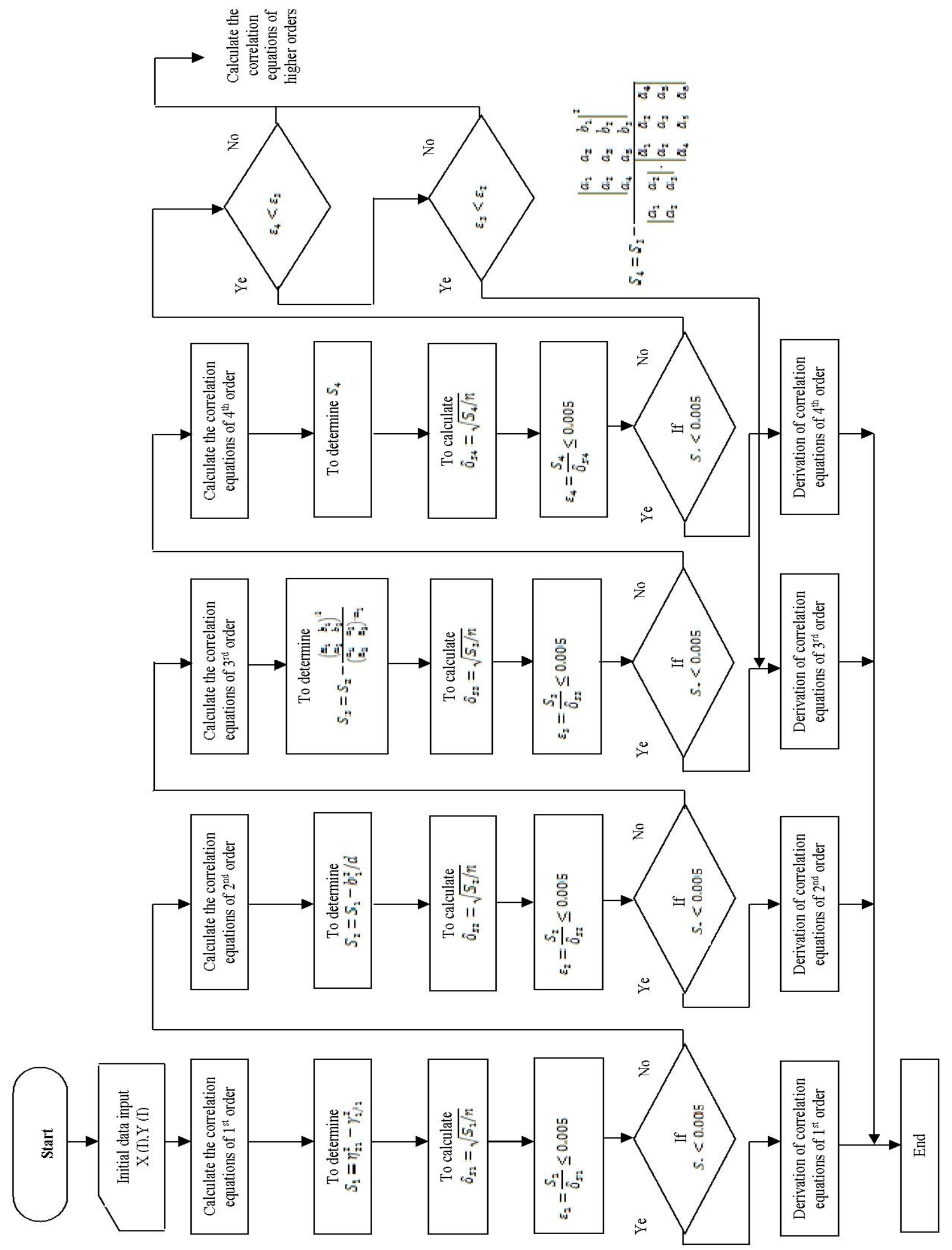

Fig. 1. Block diagram of algorithm for determining the mathematical model of power consumption and specific electricity consumption. 


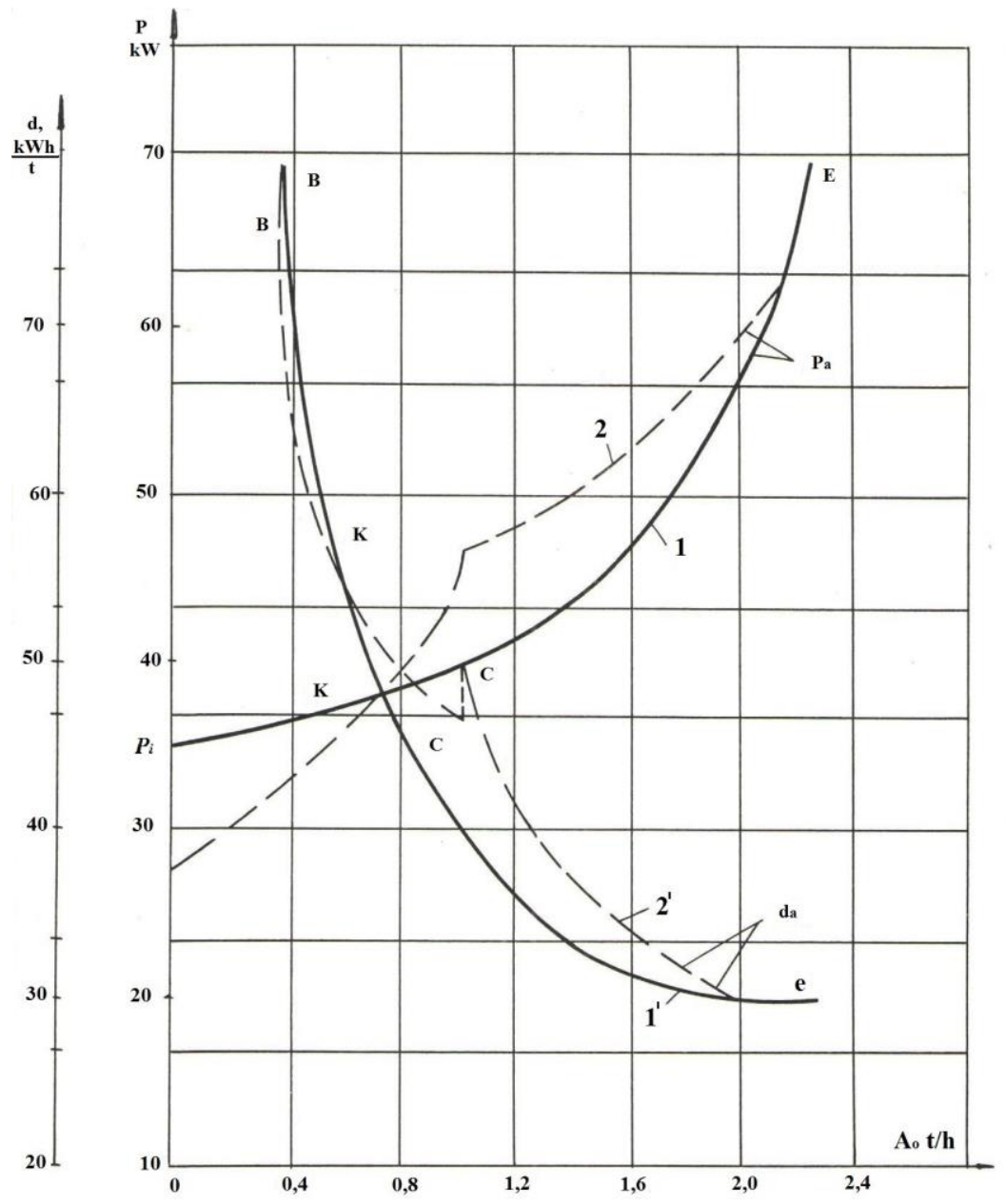

Fig. 2. Energy characteristics of $P=f\left(A_{0}\right)$ and $d=f\left(A_{0}\right)$ of oil-extraction units MPSH.

1. 1' - at the operation of the brazier and two presses evenly loaded;

2.2 - at the operation of the brazier with sequential switching on of the presses.

Electricity consumption report for 2019

Table

\begin{tabular}{|c|c|c|c|c|c|}
\hline No. & Date & Wa, kWh & Wr, kvarh & $\begin{array}{c}\text { Power } \\
\text { coefficient }\end{array}$ & $\begin{array}{c}\text { Gas, cubic } \\
\text { meter }\end{array}$ \\
\hline 1 & January & 298000 & 106850 & 0.9413 & 336638 \\
\hline 2 & February & 280000 & 105210 & 0.9361 & 285811 \\
\hline 3 & March & 298000 & 113420 & 0.9346 & 298482 \\
\hline 4 & April & 284000 & 107500 & 0.9352 & 254588 \\
\hline 5 & May & 84000 & 23200 & 0.9639 & 0 \\
\hline 6 & June & 10000 & 1980 & 0.981 & 0 \\
\hline 7 & July & 6000 & 1015 & 0.986 & 0 \\
\hline 8 & August & 6000 & 1055 & 0.9849 & 0 \\
\hline 9 & September & 148000 & 50330 & 0.9468 & 152147 \\
\hline 10 & October & 320000 & 170000 & 0.8831 & 360229 \\
\hline 11 & November & 262000 & 120000 & 0.9092 & 311131 \\
\hline 12 & December & 308000 & 132000 & 0.9191 & 365433 \\
\hline & Total & $\mathbf{2 3 0 4 0 0 0}$ & $\mathbf{9 3 2 5 6 0}$ & $\mathbf{0 . 9 2 6 9}$ & $\mathbf{2 3 6 4 4 5 9}$ \\
\hline
\end{tabular}



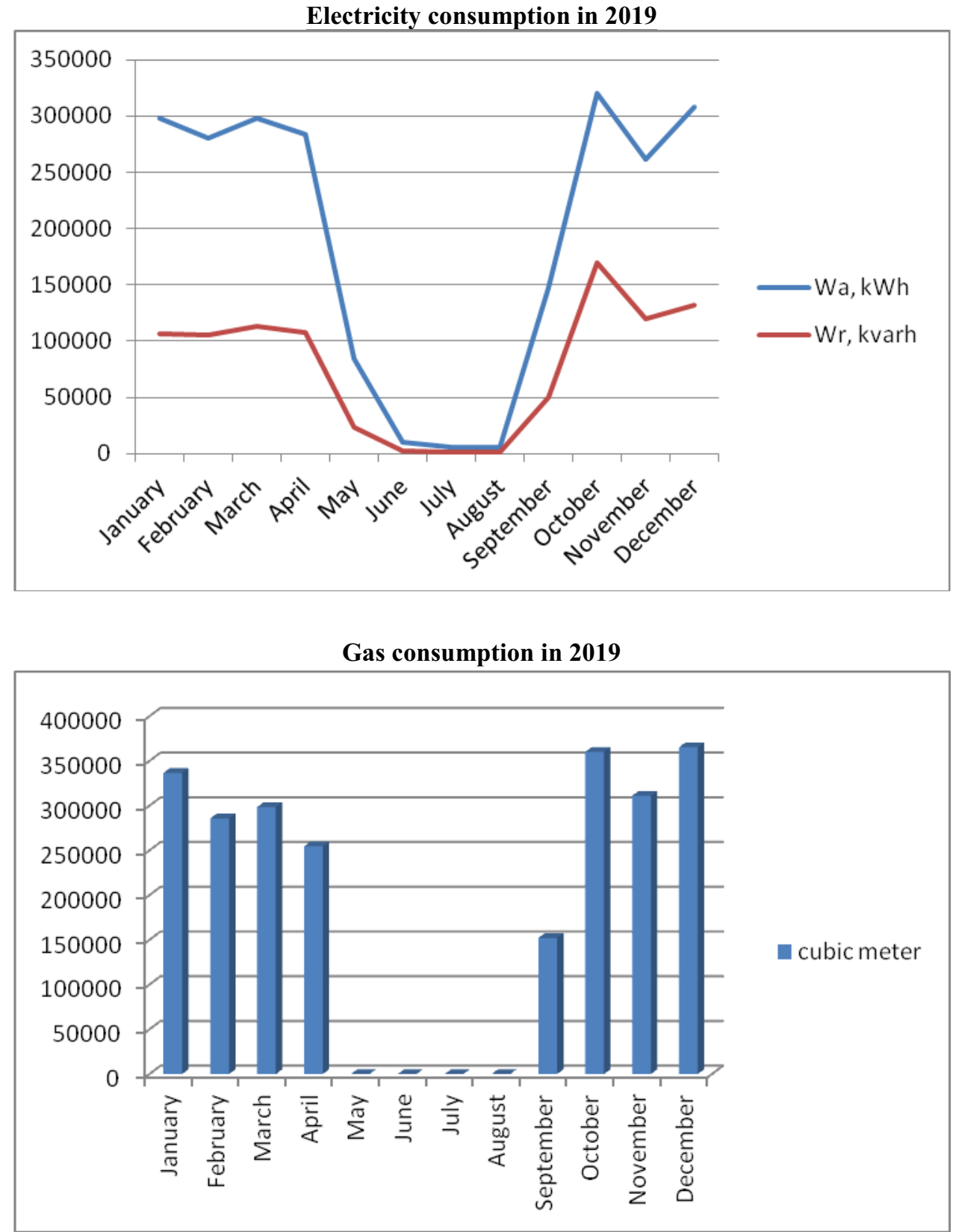

Conversion to refined oil for SCE assessment is carried out according to our proposed formula:

$$
d_{r . o}=\frac{1}{K_{u, o} \cdot K_{r . o}} \cdot d_{s}
$$

where $\mathrm{d}_{\mathrm{s}}-\mathrm{SCE}$ for seed processing, $\mathrm{kWh} / \mathrm{t} ; \mathrm{K}_{\mathrm{u} . \mathrm{o}}$ and $K_{\text {r.o }}$ - respectively, the coefficients of the yield of unrefined oils from the processed seeds.

When calculating standard indicators, the introduction of the most beneficial operating modes of electric drives of technological equipment and other organizational-technical measures that cause a change in SCE are considered.

Taking into account the different energy intensity of the industrial varieties of seeds supplied for processing, the calculations of dc were performed per unit of the conditional production of seeds of the I-II varieties, to which, using the previously obtained energy intensity coefficients, seeds of the other varieties are given.

To facilitate the analysis and calculations in operation, we have developed and proposed the nomogram for determining SCE per ton of seeds and oils in general for production (Fig. 4). 


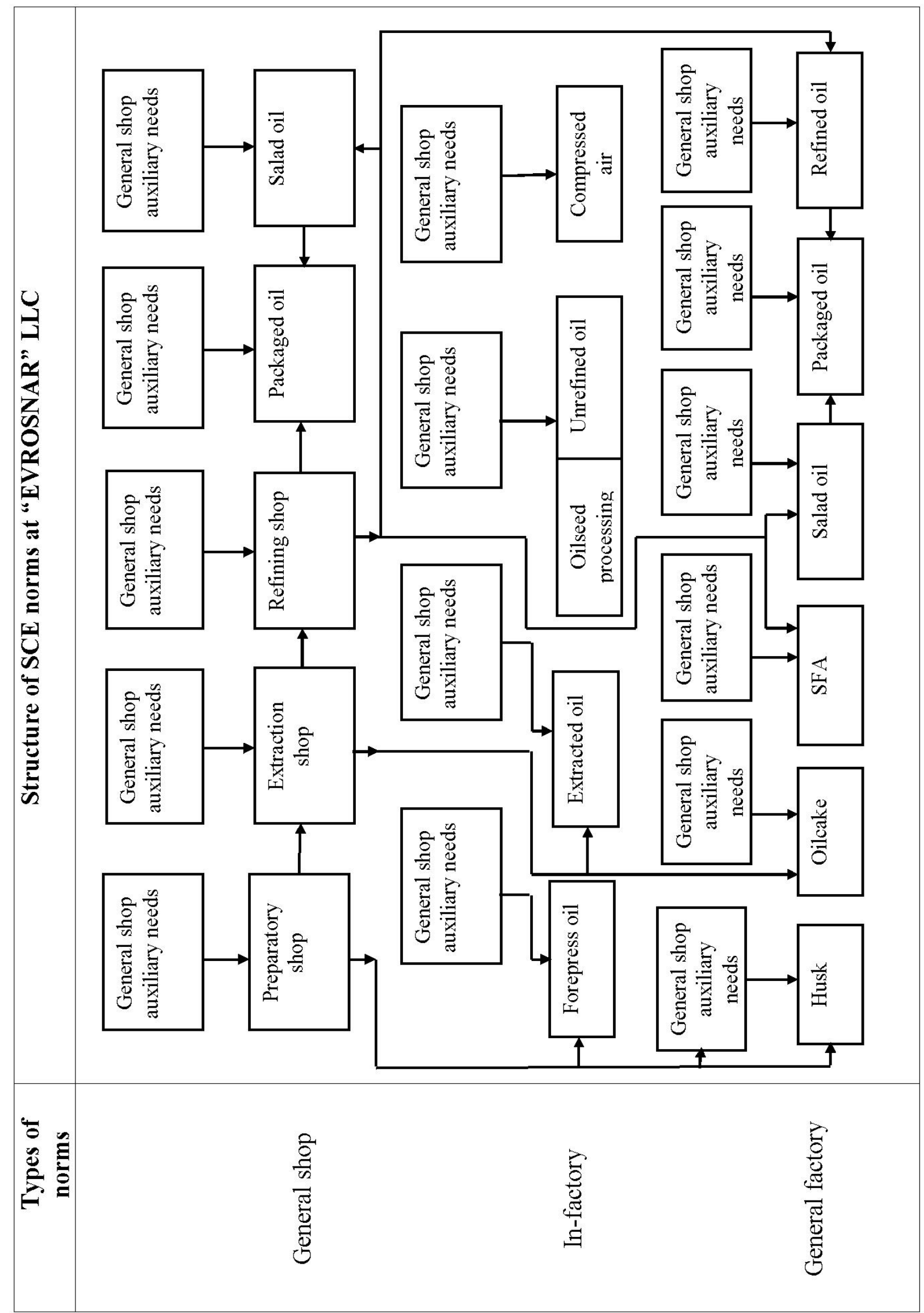

Fig.3. Structure of SCE norms 


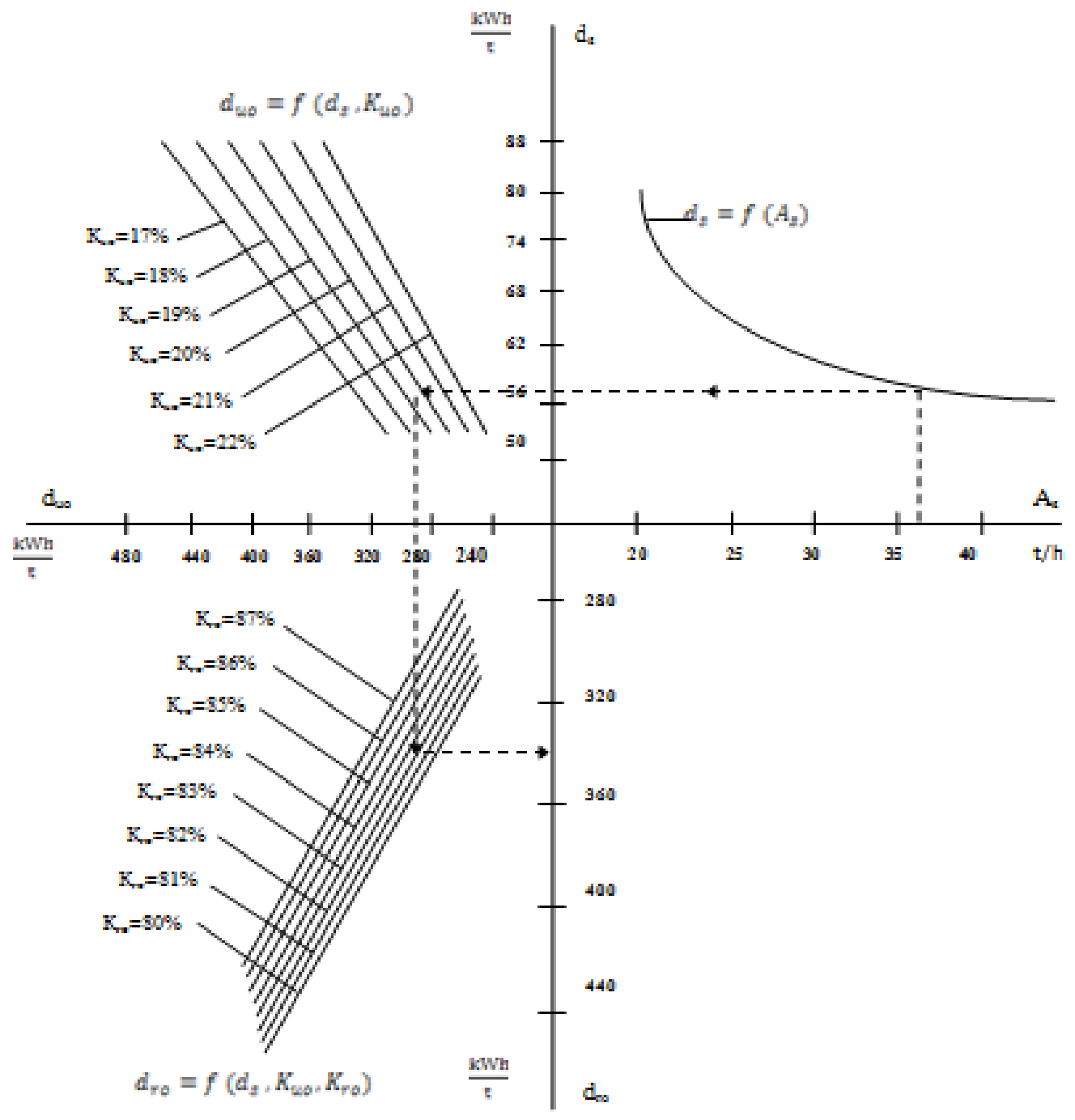

Fig. 4. Nomogram for determining the specific electricity consumption per ton of seeds, unrefined and refined oils for "EVROSNAR" LLC for given hourly seed processing

\section{Conclusions}

1. Minimum specific electricity consumption on MPSH unit with uniform loading is obtained at $90 \%$ productivity $(30(\mathrm{kWh}) / \mathrm{t})$.

2. Compiled algorithm is universal and allows obtaining mathematical models of the energy characteristics of oilextracting units of other types with a sufficient degree of adequacy.

3. The new nomenclature and structure of SCE norms, covering all types of products - husks, oilcake, FFA, salad oil and packaged oils has been proposed.

4. A nomogram to determine the SCE per ton of seeds and oils by the quantity of processed seeds and the coefficients of the yield of unrefined and refined oils (at given electricity consumption and current state of existing technological equipment) has been developed.

\section{References}

1. Energy Consumption Forecasting for Power Supply Companies// International Journal of Energy Economics and Policy. 2019, 9(1), 1-6.
2. Jalilov R.B. Research and development of methods for rationalizing electricity consumption modes in production of refined cottonseed oil. Dissertation of candidate. - Moscow: 1992, p. 258.

3. Kobzar A.I. Applied mathematical statistics. For engineers and scientific employees, Moscow: Fizmatlit, 2006, p. 816

4. Baratov N.A., Dzevensky A.Ya., Ibragimov K.Kh., Khashimov F.A., Khamidov S.I. Methods of forecasting and rationing of electric and thermal energy for the products of enterprises of the fat and oil industry. Tashkent, Fan, 1999. -83 p.

5. Rakhmonov, I.U., Reymov, K.M. (2019) Regularities of change of energy indicators of the basic technological equipment of the cotton-cleaning industry Journal of Physics: Conference Series 1399 doi:10.1088/17426596/1399/5/055038.

6. I U Rakhmonov, L A Nematov, N N Niyozov, K M Reymov and T M Yuldoshev (2020) Power consumption management from the positions of the general system theory. Journal of Physics: Conference Series doi:10.1088/1742-6596/1515/2/022054. 